\title{
The Companion paper as a complement to regular papers
}

\author{
Denis Cousineau ${ }^{\mathrm{a}, \otimes}$ \\ ${ }^{\text {a}}$ Université d’Ottawa
}

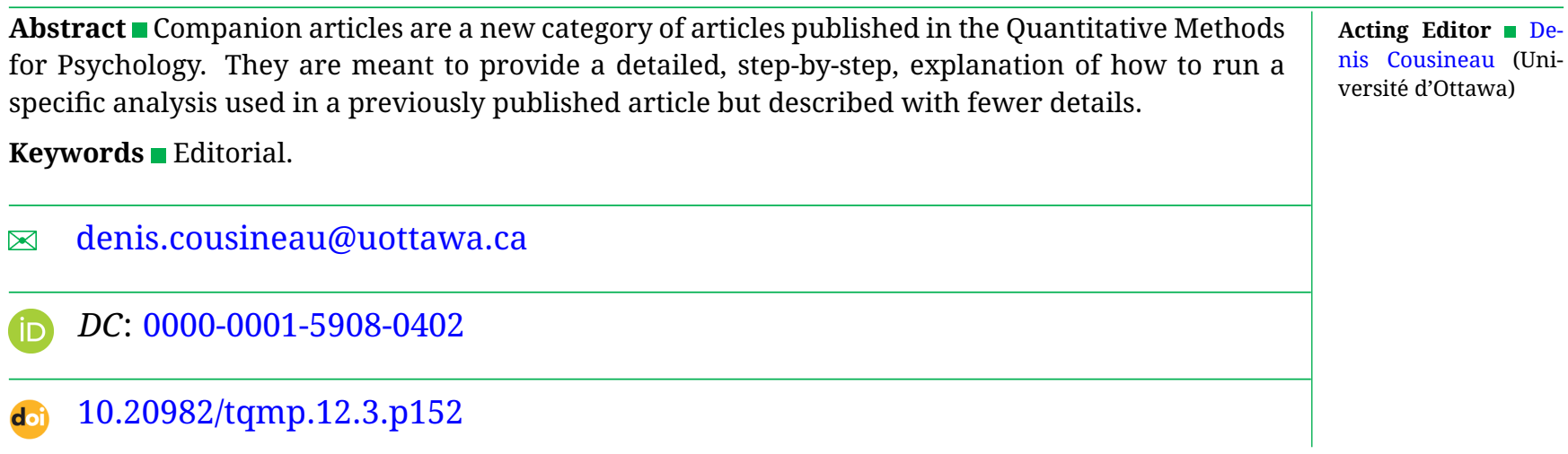

\section{Introduction}

In some research articles, it is necessary to use complex a procedure to analyze the data even though the focus of the paper is not on the procedure itself. In that case, the authors are faced with a few alternatives: (i) present the procedure at length; (ii) present the procedure at length in an appendix or in supplementary material; (iii) just present the general lines of the procedure. Of course, the last alternative is the worst one as it may impede transmission of knowledge. On the other hand, the first alternative is the most unattractive one for the readers who is more likely interested in the result. Thus, the second alternative is probably the best approach. Yet, editors sometimes pressurize the authors to shorten the manuscript. Likewise, antagonist reviewers may find enjoyment in technical appendices where they can find much material to undermine your work. Both contribute to shortened technical information where information that might be useful or even critical may not be divulged.

In The Quantitative Methods for Psychology, we offer a new possibility: to gather all the information on how to realize the analysis in a step-by-step tutorial. The Companion manuscripts will be evaluated on two major points: is it possible to replicate the analysis described? Are the various parameters or options explicitly given and the possible alternatives listed (if not fully described).

For example, if at some point, a parameter search is needed, is it indicated which of the Simplex, Newton descent, genetic algorithm or other is used? and are the starting value heuristic described? If the objective function can be selected in a list, such as Maximum likelihood, Least- square, Expected Maximization, etc., is the option chosen to reproduce the analysis of the source article clearly given and is there a rapid description of the other possible choices?

Also, the input file format should be given, with possibly screen captures showing a first few lines or typical lines. Finally, the exact software or language on which the analyses are to be run must be given (including version number used by the authors). If the analysis takes some times or uses a lot of computer memory, a general indication of these must be given.

\section{General instructions}

Here are a few guidelines to help you devise a companion article:

1. The Companion manuscript should be based on a published or accepted article (the source article) where the analysis to be described is not the main focus of the text and where it is used to analyze empirical data. It must have as subtitle "A companion to authors (year)" where authors (year) is a reference to the source article. Note that the authors of the Companion manuscript may include new names.

2. The introduction part should focus on the analysis and should briefly provide relevant theoretical background that is associated with this analysis.

3. The "method" section found in standard papers should be replaced by a step-by-step tutorial.

4. All steps should be numbered consecutively throughout this section. Short paragraphs that are marked as PLEASE NOTE can be added to indicate places where different options or alternatives are possible in the 
analysis.

5. When code is given, it should be placed in a floating object labeled as Listing (Listing 1, Listing 2, etc.). Listings have a listing caption and are in all respect similar to Figures. If outputs are given, they are likewise placed in Output floating object numbered starting with 1.

6. The result and discussion parts should exemplify results and interpret them.

PLEASE NOTE: Whenever possible, a data file should be provided with the Companion manuscript. It can be either the dataset of the source article, or a ficticious dataset that mimicks the original dataset. In that second case, the ficticious dataset could be smaller than the original dataset. The outputs given in the text should be based on the dataset made available.

\section{An example}

Röhner and Ewers (2016a), published in this issue, is an example of a Companion article describing in full length the analyses performed in Röhner and Ewers (2016b).

\section{References}

Röhner, J. \& Ewers, T. (2016a). How to analyze (faked) iat data by applying diffusion model analyses with the fast-dm software: a companion to röhner \& ewers (2016). The Quantitative Methods for Psychology, 12(3), 220-231. doi:10.20982/tqmp.12.3.p220

Röhner, J. \& Ewers, T. (2016b). Trying to separate the wheat from the chaff: construct-and faking-related variance on the implicit association test (iat). Behavior Research Methods, 48, 243-258. doi:10.3758/s13428-0150568-1

\section{Citation}

Cousineau, D. (2016). The companion paper as a complement to regular papers. The Quantitative Methods for Psychology, 12(3), 152-153. doi:10.20982/tqmp.12.3.p152

Copyright $\odot$ 2016, Cousineau. This is an open-access article distributed under the terms of the Creative Commons Attribution License (CC BY). The use, distribution or reproduction in other forums is permitted, provided the original author(s) or licensor are credited and that the original publication in this journal is cited, in accordance with accepted academic practice. No use, distribution or reproduction is permitted which does not comply with these terms.

Received: 27/08/2016 